\title{
WORLD BANK ON PUBLIC INVESTMENT PROGRAM OF TURKEY : REVIEW OF A REPORT
}

Oktar TÜREL

\section{INTRODUCTION}

In February, 1980, only weeks after the opening of the 24th January package of economic measures, Mr. Özal (then Undersecretary to State Planning Organization (SPO) of Turkey) was confirming to Mr. McNamara (then President of the World Bank) that a new approach to economic problems was enunciated as a matter of policy. He emphasized that "the... control of inflation is more important in present than the attainment of a higher growth" and "a major reorientation away from the state sector" was among the policy choices. "In recognition of this," he wrote, "we intend... (to rigorously tailor) the level of annual investment" to the resource availabilities and these intentions were "related to the size and the quality of investment programs." He also reiterated that resources will be directed to priority areas in consultation with the World Bank and demanded, in addition to a program loan to support the January 24th package, "other program assistance as appropriate."1

To these overtures, World Bank responded by sending numerous missions, with the venerable aim of helping Turkey to get out of economic crisis. And all these missions naturally tried to influence the decision-makers of the country in putting the spirit and the letter of 24th January package into effect, which has already become a pledge to the international organizations like the World Bank, IMF and OECD.

One of these missions, perhaps the most publicised one because of the authority of its chief, Professor Balassa, visited

1 Cf. Milliyet, Mar. 15th, 1980 (No. 11629). 
Turkey in May 1981 to review Turkey's policies of trade and industrialization. Which of the recommendations of Balassa mission were accepted and implemented are yet uncertain, but the hesitant steps taken in liberalizing foreign exchange regime and the changes in the legal and institutional framework of money markets in the late 1981 are likely to bear the imprint of that mission.

A less conspicuous mission led by Mr. Robert Sadove, which visited the country in October-November 1980 and completed its report presumably in September 1981, worked on an acute problem, viz. "tailoring" the public sector investment package to resource availabilities. The report of the Sadove mission (to which I shall refer as the "Report" henceforth ${ }^{2}$, is a good example of meticulousness and professionalism, which we would not wish to be left unnoticed among the paperwork pouring into Turkey and getting occasional remarks in the local press. The rest of this paper will be devoted to a review of the Report. ${ }^{3}$

\section{MACROECONOMIC IMPLICATIONS OF THE REPORT}

Although the Sadove Mission was entrusted with the task of evaluating public sector investment program, they started their investigations right from the growth prospects of Turkey and economic policies related to such prospects. Their approach was undoubtedly justified, since these issues were inseparable from the project analysis. It would, in principle, be possible to design a public investment programme, which would lead to a productive structure in contrast with the one envisaged by the architects of 24th January package. Besides, the size distribution of the public investment program necessitated such an approach. Only 35 of the 8027 projects taken into

2 The final text of the report bears the name "Turkey-Public Sector Investment Review" (Report No. 3472-TU, Document of the World Bank, Dec. 1981).

3 Although its final text was classified as "for official use only", it cannot be regarded as such; because various aspects of it were extensively reported in the Turkish press. Cf. Milliyet, (Oct. 2nd, 1981, No. 12185) and Cumhuriyet (Nov. 27-29th, 1981, Nos. 20586-8). 
the 1981 programme ( $0,4 \%$ of the total number) accounted for $44 \%$ of the total cost of project package which was TL. 5962 billion at 1981 prices. Each of these 35 projects, listed in Table 1, were to cost TL. 20 billion or over. ${ }^{4}$ If "large" projects were defined as those costing TL. 5 billion or more,, as in the Report, only 139 projects (1,7\% of the total number) accounted for $66 \%$ of the total cost.

(Table : 1)

LARGE PROJECTS OF THE PUBLIC SECTOR 1

\begin{tabular}{|c|c|c|c|}
\hline Sector & Name of the project & $\begin{array}{l}\text { Project Cost } \\
\text { (TL billion) }{ }^{2}\end{array}$ & $\begin{array}{c}\text { Evaluation } \\
\text { by the World } \\
\text { Bank }^{3}\end{array}$ \\
\hline Agriculture & Kral Kızı (Irrigation) & 55.2 & $\mathrm{E}$ \\
\hline » & $\begin{array}{l}\text { Southeast Anatolia (Ist stage } \\
\text { irrign.) }\end{array}$ & 66.8 & $\mathrm{C}$ \\
\hline » & Iğdır (Irrigation) & 21.3 & A \\
\hline Manufacturing & $\begin{array}{l}\text { Samsun Integrated Pulp and } \\
\text { Paper Mill }\end{array}$ & 45.0 & B \\
\hline » & Fourth Fertilizer Complex & 96.3 & $\mathrm{C}$ \\
\hline 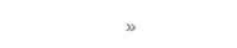 & Anatolia Fertilizer Complex & 35.2 & $\mathrm{C}$ \\
\hline » & $\begin{array}{l}\text { Soma Fertilizer Complex } \\
\text { Aliağa Petrochemical }\end{array}$ & 42.8 & $\mathrm{~B}$ \\
\hline 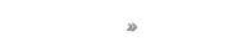 & Complex & 131.9 & A \\
\hline 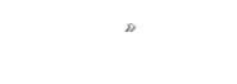 & $\begin{array}{l}\text { Izmir Refinery Expansion } \\
\text { Izmir Refinery Lub: Oil }\end{array}$ & 36.8 & $\mathrm{D}$ \\
\hline 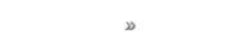 & Expansion & 50.5 & $\mathrm{D}$ \\
\hline$n$ & Middle Anatolia Refinery & 100.6 & $\mathrm{D}$ \\
\hline » & İsdemir Stage I Expansion & 63.0 & A \\
\hline » & İsdemir Stage II Expansion & 328.0 & $\mathrm{D}$ \\
\hline 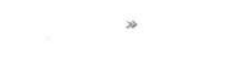 & $\begin{array}{l}\text { Sivas Integrated Steel Mill } \\
\text { Expansion of Seydişehir }\end{array}$ & 191.7 & $\mathrm{C}$ \\
\hline » & Aluminium Plant & 31.6 & C \\
\hline » & Mociern arms (MKE) & 27.6 & B \\
\hline 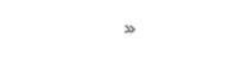 & $\begin{array}{l}\text { Tümosan Tractor Plant } \\
\text { Ist Electromechanical }\end{array}$ & 30.8 & $\mathrm{D}$ \\
\hline 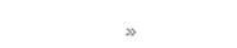 & Complex & 28.2 & D \\
\hline
\end{tabular}

4 See Table 1 


\begin{tabular}{|c|c|c|c|}
\hline * & $\begin{array}{l}\text { Intezrated Manufacture of } \\
\text { Diesel Engines }\end{array}$ & 36.4 & $\mathrm{D}$ \\
\hline Mining & $\begin{array}{l}\text { Afșin-Elbistan A (lignite } \\
\text { extraction }\end{array}$ & 44.2 & A \\
\hline " & $\begin{array}{l}\text { Afşin-Eibistan B (ingnite } \\
\text { extraction) }\end{array}$ & 34.3 & $\mathrm{D}$ \\
\hline Energy & $\begin{array}{l}\text { Altinkaya Dam and Hydru } \\
\text { Power Plant }\end{array}$ & 40.8 & $\mathrm{D}$ \\
\hline$\infty$ & $\begin{array}{l}\text { Atatürk Dam and Hydro } \\
\text { Power Plant }\end{array}$ & 354.4 & E \\
\hline » & $\begin{array}{l}\text { Kilıçkaya-Çamlıgöze Dam } \\
\text { and H.P.P. }\end{array}$ & 25.5 & B \\
\hline$\infty$ & $\begin{array}{l}\text { Eastern Black Sea Power } \\
\text { Scheme }\end{array}$ & 63.9 & B \\
\hline » & Karakaya Dam and H.P.P. & 109.6 & B \\
\hline$\infty$ & Afşin-Elbistan A (I-IV) Th. P. & 91.9 & A \\
\hline » & Çayırhan II Thermal Plant & 21.0 & A \\
\hline$\infty$ & Kangal I, II Thermal Plants & 21.0 & A \\
\hline$\infty$ & First Nuclear Power Plant & 102.6 & $\mathrm{D}$ \\
\hline$\infty$ & Afşin-Elbistan B (I-IV) Th. P. & 115.0 & $\mathrm{D}$ \\
\hline$\infty$ & Soma B Thermal Plant & 23.0 & B \\
\hline × & $\begin{array}{l}\text { Yeniköy III, IV Thermal } \\
\text { Plants }\end{array}$ & 25.5 & B \\
\hline Transportation & Trans-Turkey Highway & 33.0 & B \\
\hline \multirow[t]{2}{*}{$\infty$} & Arifiye-Sincan Railway & 95.0 & $\mathrm{D}$ \\
\hline & TOTAL & 2620.4 & \\
\hline
\end{tabular}

Notes :

1 Project cost of over TL. 20 billion.

2 As given in 1981 Annual Investment Program.

3 Although the Report mentions only priority projects by name, with the possible intention of avoiding political embarrasment, it gives sufficient clues to deduce the rest by implication.

Legend of the Last Column:
A: Advanced priority projects
B: Less advanced priority projects
C: To be deferred
D: To be postponed indefinitely or excluded
$\mathrm{E}$ : No definite judgement or comment; either C or D.

Source : Draft Repcrt, Vol. I, Appendices 1 and 2; Report, Vol. I, Table I. 11 and Appendices 1 and 2. 
These observations are sufficient to show that the most meaningful economic policy decisions in the early 1980's should be sought not only in esoteric issues of restrictive demand management and biases in international trade, but also in more mundane matters: Are we to go along with the Atatürk Dam? Is the Fourth Steel Mill to be built? Will we scrap TÜMOSAN projects altogether or leave them to oblivion?

But, instead of entering into a debate at the level of individual projects, it would be preferable first to review shortly some of the macroeconomic projections of the Report which are relevant to our subject. Some basic items of these projections are given in Tables 2-6, and enable one to comment on the (i) future growth prospects of the Turkish economy, (ii) external financing, (iii) sectoral investment pattern and (iv) the size of the public investment program as seen by the Bank. These issues will be summarily discussed below.

\section{Future Growth Prospects}

The growth rate of Turkey's GDP at market prices is predicted to be $4.1 \%$ p.a. on the average in the period 1981-1985. Agricultural and industrial incomes will supposedly grow by $3.1 \%$ p.a. and $6.4 \%$ p.a. respectively, while the constituents of industrial sector, values added in mining, manufacturing and energy will increase by $7.0,6.2,8.0 \%$ p.a., respectively. Readers of this paper are likely to be at pains in identifying the subsectors of tertiary activities which will push the growth rate of GDP to $6.0 \%$ p.a. in the second half of the decade as given in Table 2. It has to be noted, however, that the projections for 1986-1990 are not included in the final text and, rather disturbingly, it was argued that" "(e) economic recovery and manageable external accounts are not expected to occur before the mid to late 1980's" (Vol. I, p. 12).

Technical trivialities apart, these projections are important in suggesting that the World Bank would also consider other objectives of economic policy (e.g. economic growth) as respectable as the preoccupation with reducing the rate of inflation. 
(Table : 2)

PROJECTED GROWTH RATES OF KEY MACROECONOMIC VARIABLES

(\% p.a., at constant (1980) prices)

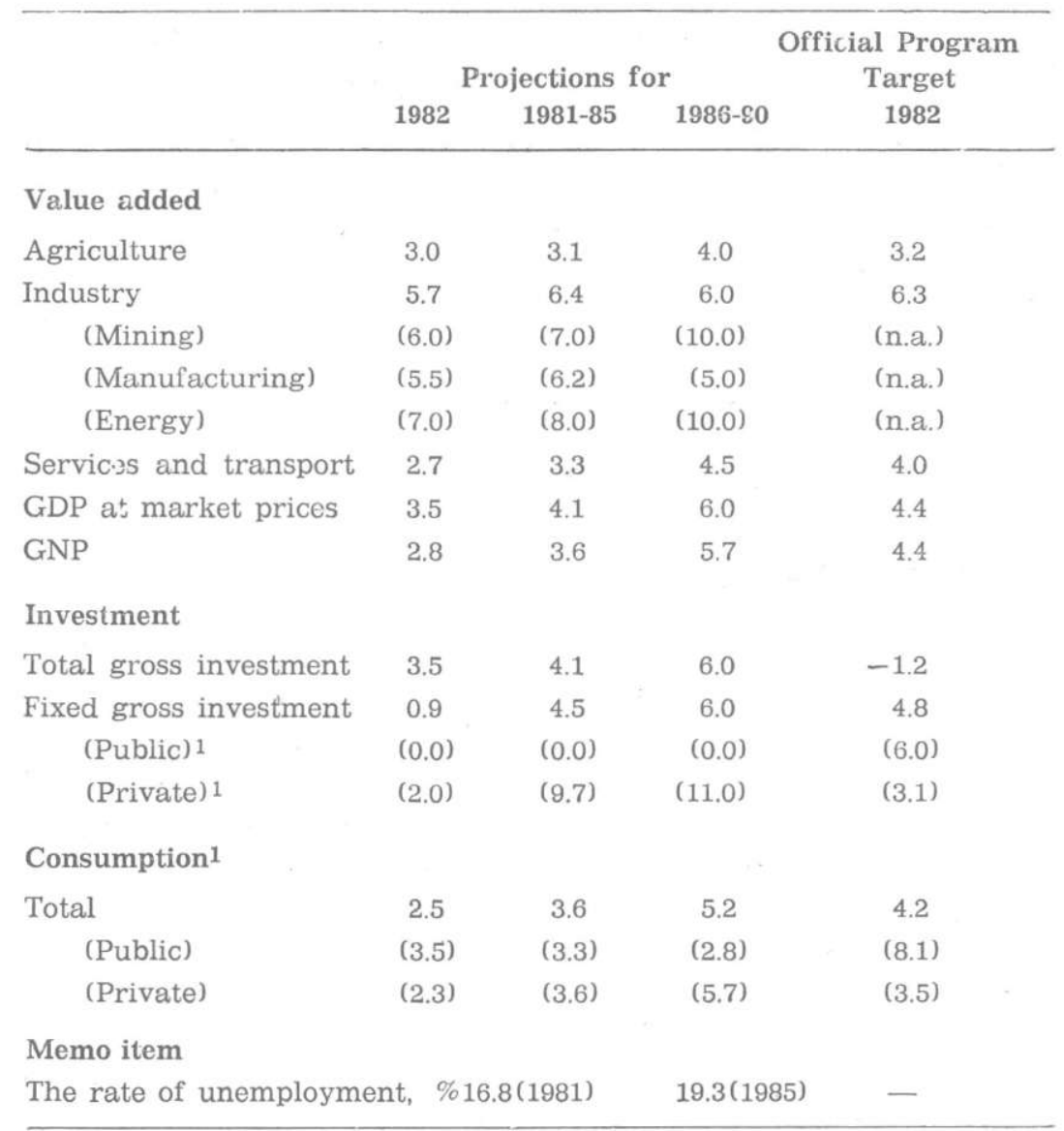

1 Computed by using the data given in the sources. n.a. : Not available.

Source: For Cols. 1-2 : Report, Vol. I, pp. 82, 92-93; Vol. III, pp. 6-8, 19; »Col. 3: Draft Report, Vol. I, pp. 11-12, Appendices 2-3;

* Col. 4: Figures announced during 1982 Budget deliberations. 
(Table : 3)

\section{BALANCE OF PAYMENTS PROJECTIONS}

(\$ Million, at current prices)

\begin{tabular}{|c|c|c|}
\hline & \multicolumn{2}{|c|}{ Estimated } \\
\hline & 1981 & 1985 \\
\hline Exports (goods and nonfactor services) & 5530 & 11160 \\
\hline Imports (goods and nonfactor services) & -9384 & -15117 \\
\hline (Oil and oil products) & $(-3959)$ & $(-6586)$ \\
\hline (Other) & $(-5425)$ & $(-8531)$ \\
\hline Trade deficit (goods and nonfactor services) & -3854 & -3956 \\
\hline Interest payments, net & -1280 & -2564 \\
\hline Workers' remittances & 2500 & 3354 \\
\hline Other factor incomes, net & - & -120 \\
\hline Factor service incomes, net & 1220 & 670 \\
\hline Balance of payments deficit & -2634 & -3287 \\
\hline Amortization of public debt & -981 & -2143 \\
\hline Public medium and longterm borrowing & 2289 & 3301 \\
\hline Net direct foreign investment & 100 & 199 \\
\hline Other capital flow, gap & 1163 & 2498 \\
\hline Overall balance, financing requirement & -63 & 567 \\
\hline IMF (net) & 304 & -314 \\
\hline Short term capital flows & - & - \\
\hline Change in reserve (-: increase) & -241 & -253 \\
\hline \multicolumn{3}{|l|}{ Memo items } \\
\hline Total debt outstanding & 20553 & 31274 \\
\hline Debt service ratio, $\%$ & 17.6 & 34.4 \\
\hline Real export growth, \% p.a., average & 15.6 & \\
\hline Real import growth, \% p.a., average & 4.7 & \\
\hline (Oil and oil products) & $(5.3)$ & \\
\hline (Others) & $(4.3)$ & \\
\hline
\end{tabular}

Note : Figures may not sum up to the totals because of rounding. Source : Report, Vol. I, p. 14 and Appendix 3 
(Table : 4)

DISTRIBUTION OF TOTAL INVESTMENT BY SECTORS, \%

\begin{tabular}{|c|c|c|c|}
\hline Sector & $\begin{array}{c}\text { Estimated } \\
1981\end{array}$ & $\begin{array}{r}\text { Annual } \\
\text { Average } \\
1982-1985\end{array}$ & $\begin{array}{c}\text { Allocation } \\
\text { in the IV. } \\
\text { Plan } \\
\text { 1979-1983 }\end{array}$ \\
\hline Agriculture & 11.0 & 11.3 & 12.2 \\
\hline Mining & 5.6 & 5.1 & 6.1 \\
\hline Manufacturing & 22.6 & 26.2 & 27.4 \\
\hline Energy & 13.6 & 11.5 & 10.6 \\
\hline Transport+Communication & 17.6 & 17.0 & 16.3 \\
\hline Tourism & 0.9 & 0.8 & 1.2 \\
\hline Housing & 18.0 & 19.5 & 14.6 \\
\hline Education & 3.1 & 1.9 & 4.8 \\
\hline Health & 1.4 & 0.9 & 1.4 \\
\hline Other Services & 6.3 & 5.8 & 5.5 \\
\hline TOTAL & 100.0 & 100.0 & 100.0 \\
\hline
\end{tabular}

Note : Figures may not sum up to the totals because of rounding.

Source : Cols. 1-2 are computed using the Report, Vol. I, Table 1.4; Col. 3 is taken from the Fourth Five Year Plan (1979-1983) p. 215.

As regards the expenditure components of GNP one is likely to detect traces of a philosophy which considers all economic activities of public sector as detrimertal to public welfare, whereas all private spending is seen beneficial to it. Here public consumption is supposed to increase by $3.3 \%$ p.a. in the period 1981-1985, barely keeping pace with the population increase, and real public spending in fixed capital is kept constant throughout the 1980's at its 1980 level. The reason for this preference is clear: "If the public sector is allocated too large a share of investible resources, the private and export sectors inevitably be "squeezed out"". (Vol. I, p. 32) $)^{5}$ And although "(r) ecently there has been a move towards more export oriented and less capital intensive activities in the industrial sector,...

5 Cf. also the paragraphs in Vol. I, pp. iv-vi. The argument in Vol. I., p. ii may not be sufficient to prove that public investment is inflationary, whereas private investment is not. 
(Table : 5)

1981 PUBLIC INVESTMENT PROGRAM

(TL. billion, at 1981 prices)

\begin{tabular}{lrrrr}
\hline & & \multicolumn{2}{c}{$\mathbf{1 9 8 1}$ Allocation } & \\
\cline { 3 - 5 } Sector1 & & & $\begin{array}{c}\text { \% of total } \\
\mathbf{1 9 8 1}\end{array}$ & $\begin{array}{c}\text { \% Dist. of } \\
\mathbf{1 9 8 0} \\
\text { Program }\end{array}$ \\
\hline Agriculture & Total Cost & Amount & Program & Progran \\
Mining & 692.7 & 84.2 & 12.6 & 10.0 \\
Manufacturing & 388.1 & 56.5 & 8.4 & 9.9 \\
Energy & 1870.0 & 137.6 & 20.6 & 21.4 \\
Transport+Communication & 1580.6 & 153.1 & 23.0 & 20.5 \\
Tourism & 900.6 & 120.9 & 18.1 & 19.1 \\
Housing & 26.2 & 5.0 & 0.7 & 0.8 \\
Education & 82.7 & 13.3 & 2.0 & 2.2 \\
Health & 82.0 & 33.1 & 5.0 & 5.8 \\
Other Services & 45.1 & 14.6 & 2.2 & 2.4 \\
\hline TOTAL & 292.2 & 48.9 & 7.3 & 7.9 \\
\hline
\end{tabular}

1 Sectors are regrouped so as to conform the Annual Investment programs.

Note : Figures may not sum up to the totals because of rounding.

Source : Report, Vol. I, Table 1.7.

(Table : 6)

APPROVED AND RECOMMENDED 1981 PUBLIC SECTOR INVESTMENT PROGRAM

(TL. billion, at 1981 prices)

\begin{tabular}{lccrc}
\hline & $\begin{array}{c}\text { 1981 } \\
\text { Approved } \\
\text { Allocations }\end{array}$ & $\begin{array}{c}\text { Implied } \\
\text { Investments } \\
\mathbf{1 9 8 2}^{2} \mathbf{8} \mathbf{2}^{\mathbf{2}}\end{array}$ & $\begin{array}{c}\text { Bank } \\
\text { Recommendations } \\
\mathbf{1 0 8 1}\end{array}$ & $\mathbf{1 9 8 2 - 8 5}$ \\
\hline Agriculture & 84 & 552 & 87 & 351 \\
Manufacturing & 122 & 1011 & 138 & 350 \\
Transport and Communication & 119 & 651 & 119 & 500 \\
Energy & 213 & 2242 & 229 & 896 \\
Housing & 13 & 54 & 15 & 60 \\
Education and Health & 48 & 216 & 48 & 143 \\
Others (including mining) & 67 & 242 & 44 & 220 \\
\hline TOTAL & 667 & 4968 & 675 & 2700 \\
\hline
\end{tabular}

1 Energy-related investments in mining, manufacturing and transport sectors are classified under "Energy".

2 World Bank estimates, based on projects in pipeline.

Source : Report, Vol. I, Table I.10. 
over $60 \%$ of the 1981 allocation for public investment in manufacturing is still primarily devoted to a relatively few heavy long-gestation on-going projects in steel, fertilizers, petrochemicals and pulp and paper" (Vol. I, p. vi). These excerpts make amply clear that the cuts proposed in the public investment program are advocated primarily not because of the exigencies of public finance, but for making room for private investment to restructure the economy in the 1980 's along the lines suggested by the World Bank.

\section{The Feasibility of the Suggested Approach}

The problem with this approach is that the private sector is assumed to make up the slack left by the public sector with a vigour unequalled in the history of the last twenty years. ${ }^{6}$ With the propensity to invest having been seriously deteriorated in the last years, and with the slow rate of progress in capital goods industries as a constituent part of the industrial strategy prescribed by the World Bank, one can envisage that such a program could be feasible only at lower levels of output. At any rate, assumed rates of expansion of manufacturing output and of capital goods imports, together with the presumed inflow of private capital leave much room for doubt about the compatibility of the projected rate of capital accumulation and the industrial structure prescribed in the report. ${ }^{7}$ One is tempted to consider, how can the envisaged private investment be realized without recourse to import substitution in capital goods industries; an option much discredited by the present economic administrators of Turkey as well as by the World Bank.

The readers must not be too unfair to the mission noting that the authors of the Report also doubt that private sector will invest in such magnitudes: "Given the economic uncertainties, in Turkey and world markets, it is however doubtful that the private sector will be willing to commit itself quickly to

6 Cf. Table I.1 in Vol. I.

7 In fact, the mission would be well-advised to take heed of Mr. Durdağ, one of the consultants listed in the report, who has recently pointed out to the fact that capacity to save, in the final analysis, has to be compatible with the supply of capital goods. See his comments in İktisat Dergisi, No. 202, Sept., 1981, pp. 17-30. 
substantial investment in the near future... This year the major difficulties affecting private sector include low domestic demand, high interest rates and the shortage of credit" (Vol. I, p. 37). ${ }^{8}$ Nevertheless, "(t)he Bank's recommendation(s) are predicated on the assumption that the private sector would have the ability to produce for the world market" (Vol. II, p. 30) and we would better leave it to the Providence that private sector really does so.

\section{Why to Mow Down Public Investment Projects?}

If the necessity to reduce public investment is established on the pretext of not jeopardizing private investment, what is the appropriate action? "In fact, in 1981 program, the Government has allocated nominal amounts for roughly half of the projects that appear to be of doubtful economic viability" (Vol. I, p. iii), and "(t) he level of investment approved in the 1981 program was more or less in line with that implied in the Report's view of project priorities" (Vol. I, p. iii) ${ }^{9}$ So, why not to follow the same strategy based on selection of priorities, timing and sequencing? This is unsatisfactory to the Bank, since "... few projects have however, actually been eliminated from the program; hence there continues to be a potentially large increase in expenditures implied for the next five to seven years" (Vol. I, p. iii). In other words, one must not leave to chance the possibility of a policy reversal; hence the suggestion to give priority to two-thirds of the large projects and to postpone or delete the others (Vol. I, p. iii). Especialiy, in manufacturing sector, further analyses will supposedly show that "... perhaps as many as $50 \% \ldots$ of the large projects...require a re-evaluation" (Vol. I, p. 36). Re-evaluation in this context is euphemism; we are to learn elsewhere in the Report that this "re-evaluation"

8 The readers would take note of the fact that these comments are not in line with the "official" stance of the World Bank. Anyhow, the Report is ambiguous on the tendencies of the private sector: "Private entrepreneurs have shown a positive response to the new policy and indicated a strong willingness to invest in production for export" (Vol. I, p. 9) and "an increase in private investment in manufacturing and agriculture (for export) is expected soon" (Vol. I, p. 15).

9 See Table 6. 
implies either indefinite postponement or exclusion of the project from the program (See Table 1, last column).

\section{Balance of Payments}

The second issue to consider is the exercise on balance of payments for which we have to be thankful to the mission, since it exposes the fallacy of the argument that Turkey does not have a foreign exchange problem in the foreseeable future. ${ }^{10}$ Even under the most optimistic assumptions about export potential and import elasticities, total indebtedness of Turkey will increase together with the debt service ratio. ${ }^{11}$

What is more alarming is perhaps the fact that although the trade gap may be stabilized in constant dollar terms, the balance of payments gap will continue growing up to 1985 and the projected decline from 1986 onwards will not considerably improve servicing of foreign debt. It follows that the strategy implicit in Mr. Özal's statements made in 1981 i.e. stabilizing the balance of payments deficit at least in the medium term to be financed by workers remittances plus moderate inflows of concessionary and/or nonconcessionary credits, is unlikely to be feasible; additional financing and/or continuous restructuring of the restructured foreign debt is on the horizon.

\section{Sectoral Investment Pattern}

Thirdly, the sectoral distribution of investment proposed is also of interest, when compared with the estimated outturn in 1981 on the one hand, and with the allocation patterns of the Fourth Plan on the other (See Table 4). The following points emerge from such a comparison: (i) the criticisms levelled against previous planners that they let agriculture and tertiary activities starve because of the shortage of allocated funds are unfounded; (ii) although the mode of industrialization is differ-

$10 \mathrm{Cf}$. Mr. Özal's speech, reported in ANKA Daily Economic Bulletin Dec. 3rd, 1981.

11 The total debt outstanding in 1981 seems to be slightly underestimated (seo Table 3), but this is irrelevant to our discussion. The fact remains that Turkey's foreign debt is likely to increase by $10.7 \$$ billion in four years. 
ent than that of the Report, the relative share of industrial investment in the Fourth Plan is in accord with the reality, and, (iii) notwithstanding naivetes of all sorts (e.g. oil vs. wheat, cattles vs. machinery, etc.) Turkey has no option but to industrialize.

\section{The Public Investment Program}

The fourth issue is the size of the public investment package implicit in the 1981 Annual Program. According to the figures in Tables 5-6, public investments which can be realized in 1982-85 with "available means" in 54\% of the total outlay due to be spent. Hence the Bank proposes to defer or to discard about a third of the large projects and related investments. While it is difficult to deny that the project portfolio is considerably bulky, it must also to be remembered that this package, in its entirety, could make sense only at higher rates of growth and with a resource allocation essentially different than the one proposed by World Bank missions. ${ }^{12}$ In summary, a student of the Turkish economy should be careful not to make public sector investment program a pseudo-problem and see it in the context of present-day policy choices, i.e. subordinating all other economic objectives to the objective of reducing the rate of inflation and believing-almost metaphysically-that the extension of the public sector is inimical to general welfare.

\section{METHODS OF PROJECT EVALUATION}

Although the public investment portfolio seems considerably bulky at first sight, excessive anxiety over the inefficiency

12 We carried out two exercises to see the impacts of (i) a GDP growth rate of $5.0 \%$ p.a. instead of $4.1 \%$ p.a. predicted in the text, and (ii) devoting incremental investment to public sector and not to private sector, keeping the rate of growth of GDP and consumption the same. The former, even under the stringent assumptions about capital/output ratios, would imply an additional fixed investment of 1135 TL. billion (in five years), with no detriment to per capita consumption; and this sum would enable the Government to complete all major mining and energy projects listed in Table 1. The latter could shift 223 TL. billion to the public sector, a sum which is enough to salvage almost all projects in machine-building sector. 
which may result from spreading funds to all projects at hand is not justified. Actually, the large projects of the present portfolio need much more time for a start than was necessary in the 1960's, due to the growing size and complexities of the projects. ${ }^{13}$ Besides, one should remember that the distribution of outlays on large projects is usually skewed towards the end of the implementation period, rather than being uniform. Hence, if the planned growth rates are finally found to be untenable, a proper time-phasing in the framework of a well defined strategy could relieve the strain on government finance.

Obviously, this would be just one side of the adjustment process. Serious considerations could (and should) be given to the choices of capacity, location, product-mix and to intrasectoral division of labour and specialization. There are indications in the report to show how creative thinking over these issues would facilitate finding solutions to the cases at hand, ${ }^{14}$ when supplemented with economic calculation.

Unfortunately, this is not the option generally taken by the mission. Instead, it resorted to international comparisons of investment costs and productivities, very often treating past expenditures on projects as sunk costs. Not even formal costbenefit analyses were attempted, at least for a subset of large projects in industry. ${ }^{15}$

Such an approach is deficient on a number of grounds:

Firstly, it may not make much sense to make absolute cost comparisons with a country where the industry under consideration is well established.

13 It is even possible to argue that especially after 1975, annual investment programmes started to look less like a programme, but more like a list of projects "eligible for financing".

14 See especially the discussions over the rehabilitation of steel mills, improving capacity utilization in pulp and paper, sugar, etc. in Vol. II.

15 "Only in one important case, namely the petrochemical project, did the Bank attempt a formal calculation of economic return... In all other cases, the Bank formed its judgements based on strategic cost factors, such as investment costs and economies of scale, observed efficiences ... and availability, quality and cost of raw materials". (Vol. II, p. 41), (our emphasis). 
Secondly, observed inefficiencies in the public sector should not be taken as preordained, but as something which can (and must) be remedied by corrective measures and constant surveillance. One should not assume inefficiency to prevail in the public sector indefinitely. In fact, the report demonstrates clearly that if the inefficiencies in a set of related sectors (coal mining, transport and energy) remain, Turkey will be unable to cope with the mounting economic problems in the late 1980's. ${ }^{16}$ Thirdly, selecting projects on their individual merit seriously impair the rationale of the existing investment programme, due to the interdependence of most of the major projects involved. The mission was fairly careful in detecting interdependence when it related to transport and energy requirements of industrial projects to be discarded, but was not capable of testing whether the remaining lot is a meaningful and interdependent whole, designed to make a maximum positive impact on the entire economy in general and on less developed regions in particular. Obviously, this was a task proper for SPO, and not for the Bank, but nowhere in the report, is there an indication that such a task was actually undertaken. Perhaps, the understanding of such a necessity has led the Bank to advocate sectoral master plans (Vol. I, p. x) and the formation of intersectoral study groups (Vol. II, p. 142) in order to look for common solutions for interdependent problems. A sad note to the SPO, the raison d'etre of which was perhaps to study these issues.

Fourthly, the logical consequence of the above approach is the total neglect of the external economies and apparently this is of little concern to the mission: " $(T)$ he burden of proof would seem to be with those suggesting that there are still substantial external economies to be had in, say, the expansion of steel production or in petrochemicals production" (Vol. II, p. 42). The fact that nobody in the present economic administration is likely to stand up to this challenge does not imply the nonexistence of externalities. Viewed from this side, priority

15 This led the Bank to the recommendation that "... selective reforms, e.g. for TKI and TCDD should not wait for a general reform of all SEEs." (Vol. I, p. x). The next ones on the queue "to require urgent attention" were, not surprisingly, TEK, and TPAO (loc. cit.). 
ordering of projects based on the magnitudes of sunk costdominant principle of project selection in the Report-is bound to be weak. ${ }^{17}$ Even in the medium term, a country must weigh the pros and cons of an industrial strategy which is assumed to be accepted by default.

\section{POLICY RECOMMENDATIONS}

There are numerous policy recommendations in the Report, both at macro and at sectoral levels, including institutional change. Among macro policy suggestions, those on reforming SEEs are perhaps the most important and we would like to dwell upon them briefly.

\section{The SEE Reform}

The Report stresses the need for an overdue institutional reform in SEEs with the following objectives: (i) strenghtening management autonomy including autonomy in pricing, (ii) improving management information systems, accounting and auditing, (iii) providing better staff training and incentives for increased professional competence, (iv) reducing overstaffing. Nobody would question the wisdom of (ii), (iii) and perhaps (iv) as well, if reduction in overstaffing would imply increased output with the existing staff, instead of keeping the same level output with lower level of employment and if an extensive retraining of the public sector employees are undertaken to upgrade the existing labor force for much needed skills.

On the other hand, if the autonomy of SEEs would mean the atomization of enterprise to constituent units (plants or otherwise) and subjecting these units to the anarchy of the market mechanism, the benefits from such a "reform" are rather dubious. One is tempted to ask why the sauce for the Turkish goose (the centralization of private industry in the form of holdings, mergers and fusion with bank capital) is not sauce for the gander. There may be good reasons to think that

17 To see how grudgingly this principle is applied, the reader would be advised to examine the evaluation procedure of the Aliaga Petrochemical project (Vol. II, p. 57-61). 
at the present state of affairs, the static problem of maximizing surplus dominates the dynamic problem of the use of surplus; hence, the suggestion of autonomy. However, the basic problem seems to lie at the provision of incentives to SEE managers and staff at all levels, compatible with the objectives of economic management, however defined.

As regards the pricing autonomy, this does not seem to be the ultimate answer to the poor performance of the SEEs, since in the past two years this autonomy was either not used at all-and unlikely to be used in the future-because of the political impact of the decision involved, or, it was used in the most negative sense, with the intention to exploit monopoly positions or with eventual reduction of output to be sold at higher prices..$^{18}$ In almost all cases, no significant improvements in productivity have taken place. ${ }^{19}$

The Bank proposes the removal of price and import controls applied to the goods produced by SEEs; perhaps the best recipe to squeeze them altogether out of the market. It stresses that "(i) n principle, imports should be free, since the increased production made possible by the availability of these basic inputs could strengthen the economy and normally take precedence over imports of investment goods" (Vol. I, p. 39). This holds true, if TL. billions worth of capital invested and operated with a crew of specific skills could be switched to other activities instantaneously. The report goes on to say that "(w)ith free imports, there would be no need for price control" (Vol. I., 39). In the same vein, with no SEEs, there would be no need for statecraft.

\section{The Role and the Size of Public Sector}

As regards to the involvement of the public sector in the productive sphere, the mission recommends to make a decision

$18 \mathrm{We}$ assume here that stockpiling of unsold commodities would not continue long and quantity is adjusted instead of price. Such a solution may be favoured by the present administration, if it entails lower operating loss.

19 To cite examples of output increase in the public sector due to the prevention of labour disputes as permanent productivity gains is utterly misleading. 
to determine which activities should continue to be in the public domain. It also has an "etatist" answer: "(U)ltimately the public sector should specialize only in the basic industries and infrastructure, leaving the remainder to the private sector" (Vol. I; p. v). Basic industries were defined as "certain heavy (i.e. capital intensive) industries where private operations, at least at this time, would not be suitable: ordinary steel, fertilizer, feedstocks such as ammonia and phosphoric acid, basic petrochemicals and primary aluminum" (Vol. I, p. 38). Outside basic industries, "continued growth of SEEs will have mainly negative effect" (Vol. I, p. 38). Hence the recommendation for progressive subdivision of SEEs and divesting: "In cement, textiles, leather, shoes, meat packing, milk processing or even sugar, there may no longer be a need for a giant SEE holding for each one of thees industries... Existing SEEs in these fields should be encouraged to sell to private interests, retaining some equity and/or advancing some of the purchase money as needed to close the deal. This may be an appropriate task for the State Investment Bank." (Vol. I., p. 39) ${ }^{20}$

If one remembers the prevailing approach of present economic management to the problem of SEEs (e.g. numerous remarks by Minister of Industry and Technology, and the existence of draft bill to be discussed shortly in the Council of Ministers, etc.) ${ }^{21}$ it is difficult to decide who will be credited as the originator of ideas in SEE reform. We would better leave to the economic historians to unearth whose inspiration came first. But, disturbing facts about bailing out of some stranded enterprises (from Asil Çelik to dairy producers) would strongly suggest that advancing purchase money may not be sufficient for divesting, perhaps an additional premium ought to be offered for prospective buyers. A final hint on the sale of equities: State Investment Bank may be ill-suited for the

20 This "assignment" for the State Investment Bank (SIB) now makes clear why the World Bank missions in the last years were insistent in transferring some of the functions of the SPO to the SIB; the sequel would then be the weakening of the central planning apparatus and later turning SIB into a hedge for SEE investment and also a branch office to finance the pet projects of the World Bank, under the pretext of sound economic calculation.

21 See, i.a. Cumhuriyet, Dec. 4th, 1981 (No. 20593) 
purpose because of its proclivity to bureaucratic traditions, stockbrokers ("Bankers" as they are known in Turkey) would do a better intermediation.

\section{Sector Policies}

The report extensively deals with sector policies to which we now turn.

Agriculture: The Bank is disappointed to see that the 1981 Annual Program introduced few changes from the investment strategy of the past: "The bulk of investment...is still devoted to slow-gestating irrigation projects and (the program) hardly differentiates between (the advanced) and the new or hardly started ones (Vol. I, p. v). Few would deny (i) that quite a number of agricultural projects defies "evaluation by any objective means" (Vol. II, p. 4), (ii) that the present administrative mechanism for extension services, support policies and institutions dealing with trade and/or production is in an urgent need of overhaul, (iii) that more attention should be paid to on-farm developments. However, a reorientation of investment away from major infrastructure projects (which revolutionize agriculture both in terms of organization and cultivation practice) does not seem to be justified. "Oversized" program of DSI could be trimmed by careful phasing as most of other cases..$^{22}$

The proposals to abolish the monopoly of TMO in the grain trade and to expand credit to private or quasi-private investment together with the complete absence of a reference to agricultural cooperatives are not surprising because of the pervaise Smithian conviction of the superiority of private initiative.

Transport: One can hardly do anything but admire the mission's insight into the deep-rooted problems plagueing the

22 It is peculiar to see that people who complain of the burden of public investment portfolio were among the ones who were responsible in increasing the number of large irrigation works of DSI from 115 to 142 in the 1981 programme (Cf. Vol. II, p. 16). 
sector, i.e. (i) the lack of an integrated approach to modes of transport, and (ii) the orientation of bulk transport to road transport, resulting a wasteful and energy-intensive transport model. Pointing out to the need to a transport master plan, it is advocated that new major investments in railroads should not be undertaken. It is also argued that many of the inefficiencies in the rail transport emanate not from the inadequacy of investment, but from poor management (Vol. I, p. 41), hence the prescription of palliatives like the reneval of track and rolling stock, more rational traffic operations, improvements in marshalling yards and signalling devices, etc. (Vol. II, p. 141). Although there is much room for improvement in existing operations, the proposed strategy of delaying a major investment program seems debatable, taking into account the imminent and unmanageable rehabilitation of main highway arteries. Consistency demands that it we scrap Arifiye-Sincan Railway because of its unconfirmed returns, we have to do the same thing for the pet project, the Turkish section of Trans-European Motorway, to which considerable sums are to be allocated with no sound economic justification.

Energy: If present trends continue, argues the Bank, the energy bottleneck will assume more serious dimensions in the late 1980 's and suggest a program based on the twin principles of (i) resource development and (ii) demand management, including an industrial retrofitting program to reduce energy use to world norms of efficiency, and energy conservation measures extending from household consumption to transport and industry. The mission also expresses doubts about the accomplishment of the massive tasks lurking in the 1980's and rightly puts the emphasis on increasing the proficiency of, and continuity in, the cadres entrusted with the carrying out of the energy program. Other suggestions are the familiar praises of the market forces, in the World Bank style (opening up of the SEE's operating in this sector to market forces, greater pricing autonomy, etc.) The suggestion to split TKI into firms specializing in lignite and hardcoal operations is in line with the "atomization" principle mentioned earlier. Besides first halving the size of a major problem, and trying to solve the first part (i.e. lignite operations, which is identified as the principal bottleneck in the decade) has also a rationale of its 
own. The identification of coal operations as the kingpin of the energy program is unquestionably correct.

Industry : The Turkish economists and administrators should be thankful to the authors of the Report for their candour in explicitly writing how they conceive industrial development: "...There is considerable potential for expansion in industries which would exploit Turkey's comparative advantage such as processed food, textiles and clothing, leather... products, furniture and wood products, light engineering products, industrial equipment, etc. All these industries have certain things in common. They are typical nonprocess industries. They only require small and medium scales of plants and can thus evolve from existing establishments. They generally have a low capital intensity, hence are rich in employment generation. Many of them are complementary to large industries, involving separable manufacturing operations such as craft or precision handwork, simple operations of assembly, mixing and finishing" (Vol. II, p. 79, our emphases). The lines speak for themselves.

All the industries cited above except engineering industries have weak complementarities with other industrial activities, and since the public sector involvement in machinebuilding is vehemently opposed by the mission, ${ }^{23}$ one could safely read "large industries" as "multinationals". The proposal to reduce the future growth of capital goods industries to subcontracting to multinationals and the insistence upon "non-process" industries should be nothing but instructive. ${ }^{24}$

The second volume of Report extensively deals with the subsectors of industry and contains expert scrutiny of the most of the major projects in the 1981 Program. The lack of space forbids us to comment on the individual projects at large. But the approach of the Bank to the engineering industries differs much from that of the Fourth Plan; this is not a matter of differing in project evaluation, but a matter of substance. Although the Bank admits that "the question of the appropriate

23 Vide infra, also Vol. II, pp. 37-38 for truck and tractor engines projects.

24 See also Vol. I, pp. 38-39. 
strategy for Turkish entry, in a more serious way, in the engineering sector is too vast a topic to be successfully handled within the context of the present Mission", (Vol. II, p. 36), the Bank is well-informed to reach the judgement that "(c) hanges should be made in the pattern which involves regionally dispersed giant complexes in the state sector to produce trucks, tractors, locomotives, machine tools, construction equipment, textile machinery, etc." (Vol. I. p. 38) and to suggest scrapping away all these projects. This does not fall far short of a double standard.

A final and self-explanatory excerpt on the much debated projects of truck and tractor plants, which, in the recent past, were made objects of derision in some quarters: "Nevertheless, it seems useful to continue to search for a longer term viable solution to the integral manufacture of trucks and tractors in Turkey. Several factors favor such production. First, the market is large, and together with potential for exports to neigbours like Iraq and Iran, should be able to support plants of minimum economic size. Second, this type of production could be relatively labor intensive... Third, it would be a way out of the blind alley of assembly. Fourth, the truck and tractor industries are rich in "external economies"; the technical and management skills required by suppliers to these industries, particulariy in operations such as casting, forging and gear-cutting, would be a tremendous asset in developing other engineering industries. Fifth, the Turkish engineering industries have now reached a stage of development (in technology, equipment, manpower) where new departures are possible..." (Vol. II, p. 68, the emphases are ours).

\section{CONCLUSION}

There is no doubt that a considerable part of the recommendations made in the report will fall to receptive ears in the present Turkish economic management. It remains to be seen to what extent these recommendations will make their way into the 1982 Annual Program and Budget. Even if they will not, it does not imply that the two parties differ in the diagnosis of the malaise and the cures for it. It is rather an 
indication of the existence of social and political constraints under which policy makers operate.

It must now be clear that the Report reviewed is not an ordinary one, made up of 'do's and 'don't's of fastidious sector specialists. Actually, the World Bank, with its stock of able experts, hardware and software, accomplished an enormous task and together with the output of the Balassa mission, drafted a blueprint for a 10-year perspective plan for Turkey. It is now incumbent upon the Turkish goverment to formulate its own vision of the medium term, instead of making vague statements about the sunny days to be reached after " 3 to 4 " years of hardship

Dec. 17th, 1981

Ankara 